\title{
METAPHOR AND THEOLOGICAL REALISM
}

\section{SEBASTIAN GÄB}

University of Trier

\begin{abstract}
In this paper, I argue that there are indispensable and irreducible metaphors in religious language and that this does not threaten a realist interpretation of religion. I first sketch a realist theory of religious language and argue that we cannot avoid addressing the problems metaphor poses to semantics. I then give a brief account of what it means for a metaphorical sentence to be true and how metaphors can refer to something even if what they mean is not expressible in literal terms. Finally, I discuss how this realist theory of metaphor influences our understanding of negative theology and gives a new perspective on religious pluralism.
\end{abstract}

\section{THEOLOGICAL REALISM}

What is theological realism? According to a first, naïve understanding it is the view that what religious beliefs are about is real, i.e., that it exists independently of us. But what does it mean to say that religious objects are real? My approach is to treat this as a semantic question, as a question about the meaning of religious language. Theological realism in this sense is a theory of religious language, or, more precisely, a theory of meaning for a certain class of statements rather than for the objects of these statements. Without going into the details I would suggest to characterize a realist understanding of religious language through four aspects: truth-conditionality, strict valence, evidence-transcendence and reference. So if someone holds a realist view of religious language, he will maintain that religious sentences have truth-conditions, which determine their propositional content; he will also interpret these truth-conditions as conditions of realist truth, which means that every 
sentence is strictly valent (it has a definite truth-value, even if we are unable to determine it; there are no truth-value-gaps) and that its truth is evidence-transcendent (the sentence is true or not independently of our actual or potential knowledge). What do I mean by that? Let's take the following sentence as an example:

'Christ has risen from the dead.'

A theological realist will understand this sentence in a way that implies the following:

(a) 'Christ has risen from the dead' is true if and only if Christ has risen from the dead. This also implies that 'Christ has risen from the dead' means exactly and only that Christ has risen from the dead, and not that it is good to live one's life from the perspective of eternity or that we should act charitably against each other.

(b) The sentence is definitely true or not true; either Christ has risen, or not.

(c) The truth of the sentence does not depend on our language, our conceptual scheme, our cognitive powers or other. Whether Christ has risen or not is a question only of facts, not of the conditions of our perceiving these facts.

(d) The sentence's truth-condition is a function of its semantic values, i.e., the sentence is true if and only if the general term 'risen from the dead' applies to the person to which the singular term 'Christ' refers.

Semantically speaking, this theory is unproblematic; there may be some quarrels about the correct interpretation of the central religious terms that appear in the sentence, e.g. what does 'rise' mean, or whom exactly does the term 'Christ' refer to? But these are not issues in philosophy of language; these problems are theological, not semantical. The approach will not become problematic until we apply it to religious language, especially to its metaphoric dimension, and in this paper I will try to explain why there is a problem and how we might solve it. First, I will show why it is impossible to avoid the problems that metaphor poses to theological realism and which particular challenge lies in it. Then, I will try to sketch a solution to these problems and finally I will point out some of the consequences which will result for some debates in philosophy of religion. I am going to argue for two points: first, that religious language has irreducibly metaphorical elements, and second that this is not a problem for theological realism. 


\section{THEOLOGICAL REALISM AND THE PROBLEM OF METAPHOR}

Religious language is rich with metaphors, symbols and other forms of figurative language, not only in its poetical dimension, in hymns, prayers or songs, but also in its philosophical or theological dimension, since a lot of important religious concepts are designated by metaphorical expressions. ${ }^{1}$ The term 'heaven', for example, is clearly a metaphorical concept, even if it is not immediately recognized as one today, and also speaking of Jesus as the 'son' of God is a metaphor. Further examples are notions like 'nirvana' in Buddhism, which literally means extinguishing, or 'dao' in traditional Chinese religion (literally: way), both trying to capture something that cannot be said in literal language. Metaphors are ubiquitous in religious language. But they are also in a way indispensable, since the special nature of religious objects often impedes alternative ways of speaking. The language of physics also relies on metaphors for qualitative statements, but these metaphors can without loss be replaced by mathematical expressions; in contrast, religious metaphors in most cases cannot be reduced to non-figurative language without losing their religious character. Take our talk of light-waves as an example: surely this is a metaphor drawing on the waves of the sea, which covers some essential differences (e.g. that there is no medium), but which can without loss be translated into a mathematical description of frequency, amplitude and wavelength. But if we try to give non-metaphorical alternatives to religious metaphors like 'heaven', we will find ourselves at a loss. We could find other metaphors like 'paradise' or 'afterlife', but

${ }^{1}$ I here understand metaphor in a very simple way as a kind of speech in which we are talking about object $\mathrm{X}$ in a way that is usually used to talk about object Y (cf. Soskice 1985: 15). There are other possible definitions, but for our current purpose the details of defining metaphor are less important. We might note in passing though that this definition allows us to draw a clear distinction between metaphor and symbol, since metaphor is a linguistic device, while symbol is not. There may be a certain mental process underlying both metaphor and symbol (a process of seeing-as), but both are different instantiations of this process. In fact, it is this element of seeing-as in metaphor which will be most important, while the details of defining metaphor are secondary. This also is the reason why I will not say anything on the difference between metaphor and simile: A simile is essentially based on metaphor, since it necessarily involves the metaphorical element of seeing-as. Everything is like everything in some way, so the point of a simile is to see one thing in terms of another. But that is just what metaphor does. If e.g. Christ says 'The kingdom of heaven is like a grain of mustard seed', the point is not to make us notice some trivial similarity between these two things, but to see the kingdom of heaven as a seed of mustard. He could as well have said 'The kingdom of heaven is a grain of mustard seed' and nothing would have changed. 
this will only defer the problem; or we could create non-metaphorical paraphrases like 'the state of bliss in communion with God after death', but the more these paraphrases will be precise, the less religious they will be. ${ }^{2}$ So if we cannot avoid religious metaphors, a realist theory of religious language should be able to explain their meaning.

Now there are basically three objections against the thesis that there should be a realist theory of metaphor:

(a) That metaphors don't have meaning.

(b) That, even if they have meaning, this meaning is fundamentally different from literal meaning.

(c) That, even if metaphorical meaning is essentially the same as literal meaning, metaphorical meaning is superfluous, since any metaphor can be reduced to literal language by paraphrasing it.

Against these objections I contend that metaphors are cognitive, semantic and irreducible. Let me briefly sketch my reasons for that.

(a) The idea that metaphors don't have meaning in a semantic sense is mainly propounded by Davidson. According to him, the only meaning a metaphor has is its literal meaning and therefore metaphors are in most cases simply false. ${ }^{3}$ The illusion of cognitive content is generated by pragmatics: a metaphor does not say something, but it affects us causally (it makes us notice some similarity), and these effects are usually confused with its meaning. So if I say that God is our father, according to Davidson this means just what it literally means: that God is our father, which is plainly false, since God is not my father; my father is my father. What the utterance does is make me notice something about God, just as pointing and saying 'Look!' would do. But prima facie there are some important reasons to reject this view. First, the truth-value of a statement alternates depending on whether we understand it metaphorically or not. If I say about some surgeon 'he's a butcher', this can be true when used metaphorically, and yet be false when used literally. But if two identical sentences uttered under the same circumstances have different truthvalues, their meanings must be different, which presupposes that they had meaning in the first place. ${ }^{4}$ Second, we usually treat metaphors as bearers

${ }^{2}$ And even with regard to this paraphrase we should be cautious: is 'communion with God' really not a metaphor? At least this kind of communion is quite different from communion with other human beings.

${ }^{3}$ Davidson 1978.

${ }^{4}$ Cf. Kittay 1987: 103; Moran 2001: 251. 
of truth-value and meaning. ${ }^{5}$ We can for example draw conclusions from them ('if he is a block of ice, we need not appeal to his pity') or gain knowledge (if for example someone teaches me that categories are tools) - how could this be possible if metaphors have no cognitive content? And third, how could we explain the effects of metaphor, if not through their meaning? To which fact about God is the metaphor in the previous example 'God is our father' drawing my attention, if not to the fact that God metaphorically speaking is my father? The fact can only be identified through the metaphor's meaning. If on the other hand we assume that metaphors don't have meaning, there is no criterion to decide which reaction to a metaphor is appropriate and which is not - we could never misunderstand a metaphor. ${ }^{6}$ If someone were to understand the words from the sermon on the hill 'You are the light of the world' as 'You hurt my eyes and cause skin cancer', we could not say that he did not get the metaphor, but only that it affects him differently from others. So intuitively, metaphors do have cognitive content, and in the absence of strong objections against this default position, we should stick to it.

(b) It is sometimes argued that metaphorical meaning is essentially different from literal meaning, so that metaphor is a distinct form of language for which we have to develop a special theory of meaning. But this argument is based on the dubious assumption that a clear and substantial distinction can be drawn between literal and metaphorical language, between what an expression actually means and what only figuratively. But this picture is misguiding; rather, these two are like the two ends of one and the same spectrum. This can be seen from the fact that no utterance contains within itself a criterion to decide whether or not it is meant metaphorically. A sentence like 'Tom is a gorilla' is, without any context, neither metaphorical nor literal. If it is uttered while someone is explaining to me the different monkeys in the zoo, a literal interpretation is suggested; if it is used to talk about someone's boss, it is probably used metaphorically. Not until the context is specified can we decide which sentence is metaphorical and which is not. ${ }^{7}$ But if literal and metaphorical meaning are both context-dependent, then literal meaning is not the standard-case and metaphor the deviation.

${ }^{5}$ Lycan 2000: 212.

${ }^{6}$ Ibid.

7 This point is defended extensively in Searle 1978. Also cf. Hesse (1988: 3): 'Literal use is most frequent use in familiar contexts.' 
It doesn't then make sense to assume a literal meaning as standard, and the distinction between literal and metaphorical loses its point. ${ }^{8}$ We don't need two theories, since there are not two phenomena.

(c) The final objection is that there is no special meaning of metaphor, since any supposed metaphorical meaning can be reduced to the meaning of a literal paraphrase. 'Paraphrase' in this sense is to be understood as: an expression whose meaning is exactly the same as the metaphor's, not just an approximation. Paraphrases in this sense are like translations: they have the same truth-condition. Of course, there may be some simple or dead metaphors which are paraphrasable in this sense, but interesting metaphors usually are not. One reason for this is that a metaphor's paraphrase will itself often be metaphorical. I could, for example, talk about a sharp wind and explain that this means that the wind cuts like a knife. ${ }^{9}$ But of course, the wind does not really cut like a knife, but only figuratively. The paraphrase is itself a metaphor. And if I go one step further and say that the wind feels like it would cut me with a knife, my utterance still remains metaphorical. My association of wind and cutting is metaphorical; feeling the wind in this way just means seeing the wind metaphorically as a knife. This phenomenon is rooted in a central property of metaphor, namely, its essential openness in meaning. A good metaphor opens a potentially infinite space of meaning, which a paraphrase does not. ${ }^{10}$ If I say metaphorically that Christ is a good shepherd, we may understand this as meaning that he protects us and watches over us, that he takes care for us. But a different understanding is possible: the believers are sheep, they are dumb and need guidance, and even the best shepherd will in the end milk or shear or butcher his cattle. Paraphrases usually lack this openness of metaphor, which is why they can never completely replace them.

So the theological realist must concern himself with the semantics of metaphor. But where is the challenge? Theological realism is a theory of religious language and as I just tried to argue, it is a theory of all religious language, even if it is metaphorical. So metaphorical utterances in religious language must be truth-apt, have truth-conditions and their truth-conditions are to be determined by the semantic values of their

${ }^{8}$ That does not mean that the whole concept of literalness is superfluous. 'Literal' can be understood as a limit-concept, denoting meaning in a default context. Deviations from this default context call for figurative readings.

9 This example is borrowed from Hesse 1988: 4.

${ }^{10}$ Cavell 1976: 79. 
components. Yet we are not allowed to derive these truth-conditions from literal paraphrases; the metaphorical utterance in itself must be true or false and refer to something. But under which conditions is a sentence like 'You are the salt of the earth' true and to what does a term like 'Last Judgement' refer? These questions - how can we determine the truthconditions of religious metaphors and how can we refer to something by them? - must be answered, if theological realism is supposed to be a viable theory.

\section{TRUTH AND MEANING OF A METAPHOR}

When speaking of the truth of metaphorical sentences we must be cautious not to misunderstand the term 'truth' in this context: there is no such thing as metaphorical truth, if by that we mean a special kind of truth that only metaphors have. Metaphorical sentences are not true in another way than literal sentences. Metaphors are a figure of speech, not of truth. Thus, it makes no sense to maintain that a sentence is only metaphorically true, since what decides whether or not a sentence is true are the facts and not the phrasing. So if I say 'Your room is a pigsty', this sentence will be true or false depending on the state of the room, on whether what is said agrees with the facts. But the truth of this sentence is not different from the truth of the literal sentence 'Your room is filthy and untidy'. So asking about the truth of metaphor does not mean asking about a special kind of truth, but rather asking how a metaphor's meaning and its truth-condition are constituted. Which proposition does it express and how do metaphorical propositions correspond to reality?

Now the theological realist claims that religious language, even if it is metaphorical, must be understood through truth-conditional semantics. This means that it should be possible for us to state the truth-conditions of a metaphorical sentence. But this seems to be a problem, for as I have said earlier, metaphors are essentially open in their meaning; if they have no definite, univocal meaning, then how can there be a meaning at all? After all, a predication draws a line between all things in the world to which the term applies and those to which it does not. But if metaphors cannot draw a clear line, they seem to be unable to predicate anything at all. But then again, I pointed out earlier that metaphorical utterances intuitively do have truth-conditions, since they can be true or false. But then what is the sentence's truth-condition? 
Let's take another example: in The Tempest, Prospero says:

We are of such stuff $\mid$ As dreams are made on. ${ }^{11}$

If we assume that this sentence, like any other, expresses a proposition, then the disquotation schema should hold for it:

'We are of such stuff $\mid$ As dreams are made on' is true if and only if we are of such stuff as dreams are made on.

Unfortunately, this schema is not very instructive, since objectlanguage and metalanguage are the same and since, which is more important, we have no other expression in the metalanguage which could be substituted for the metaphor. If my previous arguments are sound, the metaphor can neither be replaced nor paraphrased by a literal expression; so the only way to fully state the cognitive content of the metaphorical sentence is to use the same metaphor again. Thus, in a way the propositional content of the sentence is ineffable, or at least can only be expressed in one single, not absolutely precise way. ${ }^{12}$ It could be described, adumbrated, sketched, but not explicitly said other than metaphorically. But how can something which cannot clearly be said, express a proposition?

First of all we should note that it obviously does. We usually don't regard utterances as devoid of meaning just because there is no way to explicate their content other than repeating them. Even for simple, literal statements like 'The apple is red', we have no way to state their cognitive content, but this does not block us from treating them as meaningful. ${ }^{13}$ So it may be difficult or even impossible to state the propositional content of a metaphor in other words, but this alone is no objection against the existence of any such content. This should not surprise us: there is a remarkable parallel between metaphor and ostensive language. For example, I could say about someone that his voice sounds like Frank Sinatra's; or about some fruit, which someone does not know, that it tastes like lemons. In both cases, there is no other way to state the truthcondition of the sentence than to repeat the sentence. I cannot say how the voice sounds or how the fruit tastes by listing their various qualities; I cannot say (with words) what makes someone's voice sound like Frank Sinatra's. Nevertheless we would not dispute the fact that this sentence

${ }^{11}$ The Tempest, Act 4, Scene 1.

12 To be sure, it is only ineffable in our language. As Henle (1949) nicely demonstrates, ineffability is a relational predicate: something is ineffable in some language, which means that it could well be expressible in other languages.

${ }^{13}$ Goodman 1979: 126. 
expresses a proposition and that it without a doubt has cognitive content, since it can be true or false, depending on what the voice really sounds like. If we accept that there are facts about this voice and truth-conditions of my statement about it, we must also accept that there are propositions, too, which are expressed by the sentence in question.

Thus, it is also no objection against metaphorical propositions to postulate (as John Searle does) a principle of expressibility, according to which every meaning in a given language can be expressed exactly. ${ }^{14}$ That is without a doubt true, but gives us no reason to assume that metaphors have no meaning. This would only follow if we confuse 'exactly' with 'literally', for a metaphor does express its meaning as exactly as any other sentence, although there may be no literal way to state the same content. All that follows from the principle of expressibility is the trivial fact that if metaphors have meaning then it must be possible to express this meaning; but it does not follow that there must be another way of expressing this meaning. It is conceivable and consonant with the principle that a metaphor is the only possible way to exactly express some meaning.

The basic assumption behind the idea that a metaphorical sentence could only have cognitive content if this cognitive content can somehow be said, is that propositions are purely linguistic phenomena. Only given this premise does it follow from a lack of a literal paraphrase that a metaphorical sentence has no propositional content. But if we regard propositions as essentially non-linguistic entities, which are only captured by language, then it is possible that there are propositions which defy this linguistic capturing. ${ }^{15}$ So a metaphorical sentence's truth-condition simply is the proposition expressed; this proposition indeed can often only be expressed metaphorically, but that does not prevent it from being a proposition.

\section{METAPHOR AND REFERENCE}

This leads us directly to our next question: how is it possible to grasp the proposition expressed in a metaphorical sentence? Usually, we

\footnotetext{
${ }^{14}$ Searle 1981: 114. For problems with different interpretations of 'exactly' see Binkley 1979.

${ }^{15}$ Incidentally, this suggests that there could be a sound argument from the cognitivity of metaphor to the ontological reality of propositions, but spelling it out here would lead too far.
} 
understand the truth-condition and thereby the meaning of a sentence through the semantic values of the terms occurring in it: a simple sentence with the structure $\mathrm{F}(\mathrm{a})$ is true if and only if the general term 'F' applies to the object, to which the term 'a' refers. 'The lemon is sour' is true if and only if the concept 'sour' applies to the object the term 'lemon' refers to. Thus, the concept of reference is essential for grasping truth-conditions, and accordingly realist semantics demand that the concept of truth be founded on the concept of reference. But how do we determine the reference of a term? The traditional view developed by Frege is summarized under the slogan 'sense determines reference'. According to this position, the reference of a term is defined by the set of descriptions that determine its sense. So the term 'God' for example has roughly the sense: omnipotent, omniscient, perfectly good, eternal being that created the world, and refers to the being having these properties. But this model presupposes something we explicitly ruled out for metaphorical sentences: the possibility of paraphrase. If we wanted to state the semantic value of the expression 'such stuff as dreams are made on' from the above example in this way, we would have to give a literal paraphrase of the metaphorical sense. But this has already turned out to be impossible, since the sense is in a way ineffable. But if the sense of the sentence is ineffable, how do I know what the expression refers to? Here, it is useful to recall the debate on reference, especially the contributions of Kripke and Putnam, and to take a look at cases which seem to conflict with the traditional view. For example, I may talk to someone about Columbus, and we both believe that Columbus is the person who discovered America and first sailed around the Earth. Both are false, but even if we have no correct description of Columbus, we can nevertheless refer to him. The term's reference is not defined by the object's supposed properties, but fixed independently from them and passed on among the speakers of the language. This theory of reference is known as direct or causal theory and maintains that when we first encounter some object, e.g. water, we baptize this substance as 'water' and create a rigid connection between term and object. On this view, the specific properties of water (e.g. being $\mathrm{H}_{2} \mathrm{O}$ ) are not important, and neither need we know them nor be correct about them - 'water' would still refer to water.

Now in the same way, we can explain how a metaphor can have reference while its sense is still ineffable. Just as some experiential context is relevant for fixing the reference of the term 'water' and not 
a set of descriptions, the metaphor's reference can be traced back to some experience, too. These are parallel cases: if I say about someone that his voice sounds like Frank Sinatra's, the semantic value of the expression 'like Frank Sinatra's' is determined by perceiving the sound of that voice and nothing else. And if I say that Christ is the light of the world, this, too, is rooted in a certain experience, although it will be more complicated to give an account of this experience (maybe I am experiencing the salvific power of Christ in my life). Also, this experience need not be my own - the metaphor may be coined by someone else and then be passed on to me without me fully understanding its sense. As a consequence, this causal theory of reference stresses the importance of religious experience for understanding religious language. ${ }^{16}$ Religious experience is the primary phenomenon when it comes to fixing meanings, while definite descriptions are secondary. Only if we take religious experiences as a starting point for understanding religious language are we able to explain how we can understand metaphors in religion.

It is important to note two minor points here: first, the metaphor will, in contrast to pure names like 'water', have some connection to the relevant experience via its linguistic shape. While the phonetic sequence 'water' could in principle represent any object at all, I can only speak of God as a mighty fortress if there is some relation between my experience and the sense of the metaphor, that is, if I perceive God's strength, protection or security (and not His compassion). Second, the metaphor's reference is not my experience itself, and also not the feeling that accompanies my experience, but God's property of being a mighty fortress (metaphorically), which is identified through my experience.

\section{CONSEQUENCES: NEGATIVE THEOLOGY AND PLURALISM}

If we take together the two theses, that metaphors are irreducible in religious language and that their meaning is based on certain experiences, some interesting consequences follow for other areas in philosophy of religion. The first is negative theology, the second pluralism of religions.

(1) Negative theology maintains that we cannot predicate something positive about God; we can only say what God is not. There is a remarkable parallel to metaphor: just as metaphors cannot be reduced

${ }^{16}$ It also implies that one of the pragmatic functions of religious language is to provide a means to trigger certain religious experiences in one's audience. 
or paraphrased, talk about God cannot be translated into affirmative, positive language. But as we have seen, this quality of metaphor is no reason to deny it a cognitive content and we could postulate the same for negative theology. Even if we can neither say that God is eternal nor that he is not eternal, this is no reason to conclude that negative theology is non-cognitive, unless we make the critical assumption that a proposition is only expressed where it can be expressed in a literal, unambiguous way. If we don't accept this assumption, it becomes possible to see the negative way as a method to grasp propositions about God, without being able to clearly express them in language. And this means that there may be facts and truths beyond our linguistic possibilities. This is not a problem for realism: realism only demands that there can be no truth-value gaps and that truth is not tied to our epistemic capacities, and negative theology fulfils both. So negative theology is actually a position of extreme realism, contrary to several contemporary interpretations, which regard it as a variety of antirealism. Negative theology predicates true propositions of a reality which by their very nature cannot be expressed in another way. ${ }^{17}$ So in other words, the consequence for theological realism is that it only postulates the existence of objective truths about religious entities, but not that we necessarily have linguistic access to them (or any access at all). ${ }^{18}$

(2) Seeing direct reference and therefore religious experience as the core phenomena in the foundation of religious language opens up a new approach to the problem of religious pluralism. The fundamental problem of pluralism is to explain how the conflicting truth-claims of different religions can be reconciled. These truth-claims are based on the meaning of the respective theological statements, of course: what is claimed to be true when someone says that 'God created the world', can only be determined if we know the meaning of the relevant components and the sentence itself. But if the meaning of these terms is not, as a description theory of reference maintains, defined by a list of the object's properties, but rather by a certain experience, a lot of supposed contradictions just vanish. Take as an example the question of whether

17 Presumably, what negative theology says is rooted in some kind of mystical experience, too. But finding the contents of these experiences in theological language and incorporating them into the language of negative theology would lead too far here.

${ }^{18}$ It also follows from this that the quite popular contention that realism demands a literal interpretation of religious language (e.g. in Kaufman and Cupitt) is false. Realism demands a certain concept of truth and meaning, but not a certain kind of expression. 
there is a God: Christianity gives an affirmative answer, Buddhism denies it, which creates the contradiction that pluralism wants to bridge. But this contradiction results from our understanding of the term 'God' as 'omnipotent, omniscient, eternal being, etc.. Now if we don't understand this term descriptively, but rather metaphorically as something which is given to me in a certain kind of experience, whatever it may be, a way is found to avoid the contradiction. We should not ask how these two sentences can be logically compatible, but whether the religious experiences which the Buddhist calls 'emptiness' (shunyata) and those which the Christian calls 'God' differ in their experiential qualities. If it could be shown that there is a common core of experience behind the different descriptions, which defines the reference of these two terms, the pluralist could maintain to have found something these entities essentially have in common and thereby overcome the superficial gap between them. ${ }^{19}$ To be sure, this would involve a massive revision of all those religious beliefs which then have to be taken metaphorically, and few believers will be happy to accept this requirement. But if we want to make sense of pluralism, I believe the only way is to adopt a metaphorical-realist interpretation of religious language.

Acknowledgment. This paper was originally presented in Mainz, Germany, at a conference for the Analytic Theology Project, generously funded by the John Templeton Foundation. Reason and Belief' in Berlin, also funded by the Templeton Foundation. I thank my commentators on both events for their critical and helpful remarks.

${ }^{19}$ It is without a doubt true that on this theory we could never be sure whether the religious experiences of two different people really do have the same common core, since there is nothing to compare them to. But strictly speaking, this holds for all other experiences as well. If you and I are looking at a painting together, I can never be sure whether you are seeing the same as me, whether we are having the same experience. We could agree on the object of our experience, but not on the way this object is given to us (the erlebnis). So if this is reason to doubt the truthfulness of religious experience, it is a reason to distrust all experience. 


\section{BIBLIOGRAPHY}

Binkley, Timothy. 1979. 'The Principle of Expressibility', Philosophy and Phenomenological Research, 39: 307-325

Cavell, Stanley.1976. 'Aesthetic Problems of Modern Philosophy', in Stanley Cavell, Must We Mean What We Say? (Cambridge: Cambridge University Press), pp. 73-96

Davidson, Donald. 1978. 'What Metaphors Mean', Critical Inquiry, 5: 31-47

Goodman, Nelson.1979. 'Metaphor as Moonlighting', Critical Inquiry, 6: 125-130 Henle, Paul. 1949. 'Mysticism and Semantics', Philosophy and Phenomenological Research, 9: 416-422

Hesse, Mary. 1988. 'The Cognitive Claims of Metaphor', The Journal of Speculative Philosophy, 2: 1-15

Kittay, Eva Feder. 1987. Metaphor: Its Cognitive Force and Linguistic Structure (Oxford: Clarendon)

Lycan, William. 2000. Philosophy of Language (London: Routledge)

Moran, Richard.2001. 'Metaphor', in Bob Hale and Crispin Wright (eds.), A Companion to the Philosophy of Language (Oxford: Blackwell), pp. 248-268 Searle, John. 1978. 'Literal Meaning', Erkenntnis, 13: 207-224

Searle, John. 1981. Expression and Meaning (Cambridge: Cambridge University Press)

Soskice, Janet Martin. 1985. Metaphor and Religious Language (Oxford: Clarendon) 